University of Nebraska - Lincoln

DigitalCommons@University of Nebraska - Lincoln

$1-1991$

\title{
Cross sections for single and double strand breaks in SV-40 virus in EO buffer after heavy ion irradiation: Experiment and theory
}

Robert Katz

University of Nebraska-Lincoln, rkatz2@unl.edu

S. Wesely

University of Nebraska-Lincoln

Follow this and additional works at: https://digitalcommons.unl.edu/physicskatz

Part of the Physics Commons

Katz, Robert and Wesely, S., "Cross sections for single and double strand breaks in SV-40 virus in EO buffer after heavy ion irradiation: Experiment and theory" (1991). Robert Katz Publications. 192.

https://digitalcommons.unl.edu/physicskatz/192

This Article is brought to you for free and open access by the Research Papers in Physics and Astronomy at DigitalCommons@University of Nebraska - Lincoln. It has been accepted for inclusion in Robert Katz Publications by an authorized administrator of DigitalCommons@University of Nebraska - Lincoln. 


\title{
Cross sections for single and double strand breaks in SV-40 virus in EO buffer after heavy ion irradiation: Experiment and theory
}

\author{
R. Katz and S. Wesely \\ Department of Physics and Astronomy, 364 Behlen Laboratory, University of Nebraska-Lincoln, \\ Lincoln, NE 68588, USA
}

\begin{abstract}
Measured cross sections after heavy ion bombardment, for both single and double strand breaks of SV-40 virus in EO buffer (which emphasizes indirect effects), are consistent with the theory of Butts and Katz for 1-hit detectors.
\end{abstract}

\section{Introduction}

We have calculated cross sections for heavy ion bombardment of hypothetical point targets for which the $D_{37}$ dose is equal to that measured for single strand breaks and for double strand breaks according to the theory of Butts and Katz [1], using as the radial distribution of dose that calculated by Waligórski et al. [2]. This is essentially a $1 / r^{2}$ distribution which we have recently used for modeling the Fricke dosimeter [3] and for recalculating cross sections for dry enzymes and viruses [4].

\section{The track physics model reviewed}

Our model is based on the assumption that the effects produced by secondary electrons from $\gamma$-rays and from the secondary electrons from heavy ions ( $\delta$-rays) are comparable at the same "dose."

In this assumption we neglect any differences in the time scale of these two irradiations. We also neglect differences in the initial electron energy spectra, basing this neglect on the assumption that it is the electron slowing down spectrum rather than the initial energy spectrum which is responsible for radiation action [5]. When we speak of the "dose" of $\delta$-rays surrounding a heavy ion's path we imagine that we study the energy deposited in nests of coaxial cylindrical shells surrounding many ions. Thus the "dose" of $\delta$-rays within a shell is an average quantity over a synthetic large volume made up of equivalent shells about many ions. We use the effect produced in a macroscopic volume by a given dose of $\gamma$-rays to estimate the effect produced in the shell about our typical averaged ion. That effect is imagined to be the probability of inactivating a target as a function of macroscopic dose. Note that this probability is also an average quantity. Thus, even at large distances from an ion's path where there are very few $\delta$-rays penetrating a shell, we esti- 


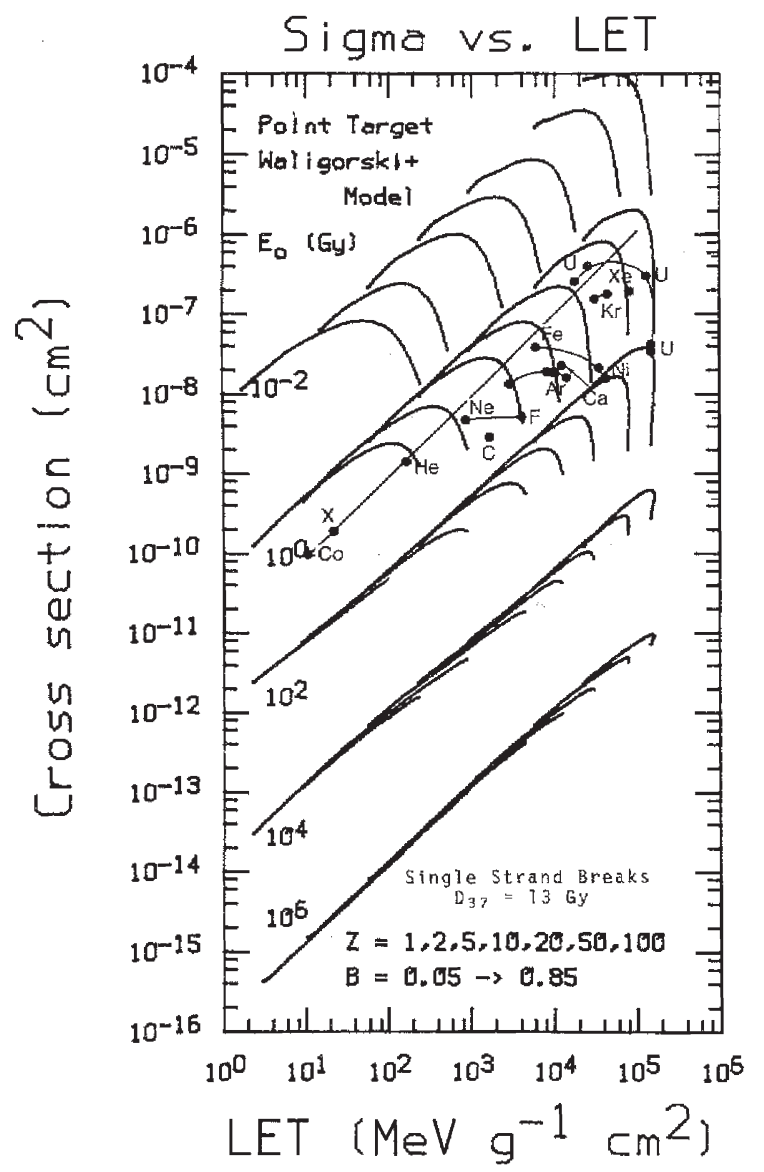

Figure 1. Experimental cross sections for single strand breaks in SV-40 Virus in EO buffer after heavy ion bombardment superimposed on a set of calculated curves for a range of $D_{37}$ values encompassing the values characteristic of many biological 1-hit detectors, which lie between 10 and $10^{6}$ Gray. From the theory of Butts and Katz, in the pointtarget model, modified by use of the radial dose distribution of Waligórski et al. (1987)

mate the effect on the basis of a similarly low dose of $\gamma$-rays where there also few secondary electrons. This procedure is "operational" in the sense that each of the several steps is accessible to experiment. Thus the survival data obtained from an $\mathrm{x}$ - or $\gamma$-irradiation is folded into the radial dose distribution to yield a radial distribution of inactivation probability whose radial integral is the cross section.

We know of no other experimentally based operational procedure which enables one to connect a calculation of the radial distribution in physical events to the radial distribution in biological effect, and hence to calculate a cross section. The cross-section is also an average quantity.

In this model, target size is of consequence only for light ions in the "grain count regime." Where the observed effect is principally close to the ion's path we average the "dose" over the target volume to compensate for its gradient. For heavy ion bombardment in the "track width regime," all targets close to the ion's path are inactivated so that the cross section is dominated by the radial extent of the delta rays and target size is of minimal importance.

\section{Results}

For this calculation we have used the $D_{37}$ dose for gamma rays as measured by Roots $e t$ al. [6]. The measured values are 13 Gray for single strand breaks and 320 Gray for double 


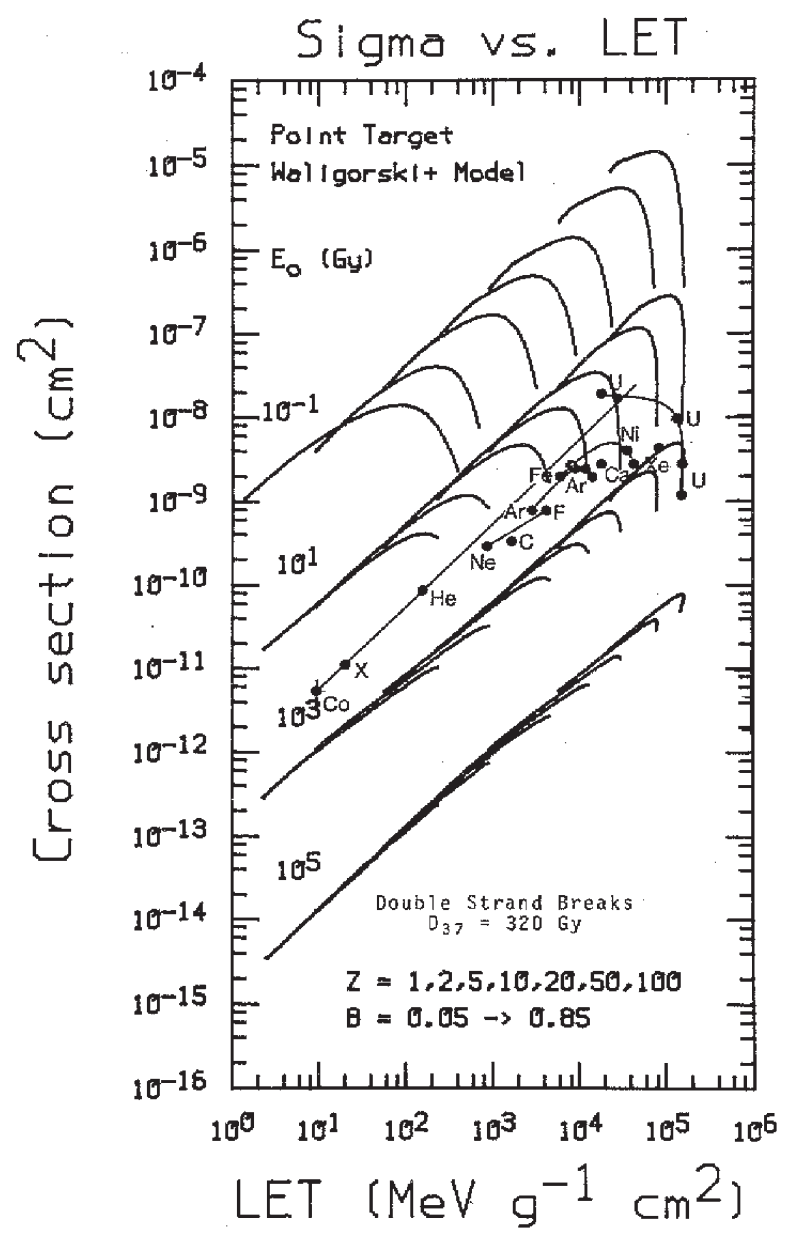

Figure 2. Double strand breaks. See caption to Figure 1

strand breaks when the virus is in EO buffer, where indirect effects predominate. Our calculations are made in the point target approximation neglecting target size.

There are no adjusted parameters. We have no need for such concepts as a "physical core" or a "chemical core."

We reproduce the data of Roots et al. for SSB (single strand breaks) in Figure 1, where we have superimposed a set of calculated curves for cross section vs. LET. A similar illustration for DSB (double strand breaks) is shown in Figure 2. There we see that the data are bracketed between curves calculated for $D_{37}$ doses both below and above the experimental values. We have chosen this method to exhibit graphically the nature of the agreement between theory and experiment. We have chosen not to display a graph in which experimental cross sections are superimposed on a set of calculated cross sections for the value of $D_{37}$ found experimentally, for its appearance is somewhat cluttered. Instead we compare experimental and calculated values in tables.

The experimental values of the cross sections, and the calculated values based on the experimental $D_{37}$ dose for $\gamma$-rays are shown in Table 1 for SSB and in Table 2 for DSB. Except for He and $U$ bombardments, the calculated cross sections lie within a factor of 2 of the data. Omitting the $\mathrm{He}$ and $\mathrm{U}$ data, the average ratio of the experimental to theoretical cross sections is 0.86 for SSB and 1.26 for DSB. 
Table 1. Single-strand breaks in SV-40 virus in "EO-buffer." Numerical values of cross sections for single strand breaks for each experimental bombardment. Shown are the atomic number $\mathrm{Z}$ of the projectiles, the LET of each ion, the experimental cross section, and calculated cross sections. Experimental data are from Roots (1989). Theoretical calculations were made using $E_{0}=13 \mathrm{~Gy}$

\begin{tabular}{|c|c|c|c|c|}
\hline Z & LET $\left(\mathrm{MeV} / \mathrm{g}-\mathrm{cm}^{2}\right)$ & $\sigma \exp \left(\mathrm{cm}^{2}\right)$ & $\sigma$ th $\left(\mathrm{cm}^{2}\right)$ & $\sigma \exp / \sigma$ th \\
\hline 2 & 1.50 E 2 & 1.30 E-09 & $5.14 \mathrm{E}-08$ & 2.52 \\
\hline 6 & 1.45 E 3 & $2.70 \mathrm{E}-09$ & 3.70 E-09 & 0.73 \\
\hline 9 & 3.75 E 3 & $5.00 \mathrm{E}-09$ & $8.26 \mathrm{E}-09$ & 0.61 \\
\hline 10 & 7.70 E 2 & $4.60 \mathrm{E}-09$ & 2.78 E-09 & 1.65 \\
\hline 18 & 2.60 E 3 & $1.25 \mathrm{E}-08$ & 9.04 E-09 & 1.38 \\
\hline 18 & 7.60 E 3 & $1.85 \mathrm{E}-08$ & $2.01 \mathrm{E}-08$ & 0.92 \\
\hline 18 & 8.50 E 3 & $1.80 \mathrm{E}-08$ & $2.01 \mathrm{E}-08$ & 0.90 \\
\hline 18 & 1.00 E 4 & $1.75 \mathrm{E}-08$ & $2.32 \mathrm{E}-08$ & 0.75 \\
\hline 18 & 1.25 E 4 & $1.50 \mathrm{E}-08$ & $2.42 \mathrm{E}-08$ & 0.62 \\
\hline 20 & 1.10 E 4 & $2.00 \mathrm{E}-08$ & $2.57 \mathrm{E}-08$ & 0.78 \\
\hline 26 & 5.70 E 3 & 3.45 E-08 & $1.87 \mathrm{E}-08$ & 1.84 \\
\hline 28 & $3.20 \mathrm{E} 4$ & $2.00 \mathrm{E}-08$ & $4.17 \mathrm{E}-08$ & 0.48 \\
\hline 28 & 3.75 E 4 & $1.45 \mathrm{E}-08$ & $3.06 \mathrm{E}-08$ & 0.47 \\
\hline 54 & 7.40 E 4 & $1.70 \mathrm{E}-07$ & $8.22 \mathrm{E}-08$ & 2.07 \\
\hline 92 & $1.60 \mathrm{E} 4$ & $2.20 \mathrm{E}-07$ & $5.65 \mathrm{E}-08$ & 3.89 \\
\hline 92 & $2.40 \mathrm{E} 4$ & 3.40 E-07 & 7.31 E-08 & 4.65 \\
\hline 92 & 1.20 E 5 & $2.60 \mathrm{E}-07$ & $1.91 \mathrm{E}-07$ & 1.36 \\
\hline 92 & 1.40 E 5 & $3.60 \mathrm{E}-08$ & $1.29 \mathrm{E}-07$ & 0.28 \\
\hline 92 & 1.35 E 5 & $3.10 \mathrm{E}-08$ & $1.58 \mathrm{E}-07$ & 0.20 \\
\hline \multicolumn{4}{|c|}{ Omitting the $\mathrm{He}$ and $\mathrm{U}$ data, the average ratio is: } & 0.86 \\
\hline
\end{tabular}

Table 2. Double-strand breaks in SV-40 virus in "EO-buffer." Experimental data are from Roots (1989). Theoretical calculations were made using $E_{0}=320 \mathrm{~Gy}$. (See caption to Table 1)

\begin{tabular}{lcccc}
\hline $\mathrm{Z}$ & $\mathrm{LET}\left(\mathrm{MeV} / \mathrm{g}-\mathrm{cm}^{2}\right)$ & $\sigma \exp \left(\mathrm{cm}^{2}\right)$ & $\sigma$ th $\left(\mathrm{cm}^{2}\right)$ & $\sigma$ exp $/ \sigma$ th \\
\hline 2 & $1.47 \mathrm{E} 2$ & $7.60 \mathrm{E}-11$ & $2.71 \mathrm{E}-11$ & 2.80 \\
6 & $1.54 \mathrm{E} 3$ & $2.90 \mathrm{E}-10$ & $2.38 \mathrm{E}-10$ & 1.22 \\
9 & $3.90 \mathrm{E} 3$ & $6.60 \mathrm{E}-10$ & $4.87 \mathrm{E}-10$ & 1.36 \\
10 & $8.20 \mathrm{E} 2$ & $2.50 \mathrm{E}-10$ & $1.47 \mathrm{E}-10$ & 1.90 \\
18 & $2.70 \mathrm{E} 3$ & $6.60 \mathrm{E}-10$ & $4.44 \mathrm{E}-09$ & 1.49 \\
18 & $7.90 \mathrm{E} 3$ & $2.20 \mathrm{E}-09$ & $1.12 \mathrm{E}-09$ & 1.96 \\
18 & $8.80 \mathrm{E} 3$ & $2.10 \mathrm{E}-09$ & $1.24 \mathrm{E}-09$ & 1.69 \\
18 & $1.05 \mathrm{E} 4$ & $2.00 \mathrm{E}-09$ & $1.38 \mathrm{E}-09$ & 1.45 \\
18 & $1.28 \mathrm{E} 4$ & $1.70 \mathrm{E}-09$ & $1.52 \mathrm{E}-09$ & 1.12 \\
20 & $1.60 \mathrm{E} 4$ & $2.40 \mathrm{E}-09$ & $1.78 \mathrm{E}-09$ & 1.35 \\
26 & $5.60 \mathrm{E} 3$ & $1.65 \mathrm{E}-09$ & $9.21 \mathrm{E}-10$ & 1.79 \\
28 & $3.40 \mathrm{E} 4$ & $3.50 \mathrm{E}-09$ & $2.98 \mathrm{E}-09$ & 1.17 \\
28 & $4.02 \mathrm{E} 4$ & $2.50 \mathrm{E}-09$ & $2.55 \mathrm{E}-09$ & 0.98 \\
54 & $7.70 \mathrm{E} 4$ & $3.90 \mathrm{E}-09$ & $6.48 \mathrm{E}-09$ & 0.60 \\
92 & $1.70 \mathrm{E} 4$ & $1.60 \mathrm{E}-08$ & $2.63 \mathrm{E}-09$ & 6.08 \\
92 & $2.45 \mathrm{E} 4$ & $1.40 \mathrm{E}-09$ & $3.46 \mathrm{E}-09$ & 4.05 \\
92 & $1.30 \mathrm{E} 5$ & $8.50 \mathrm{E}-08$ & $1.21 \mathrm{E}-08$ & 0.70 \\
92 & $1.48 \mathrm{E} 5$ & $2.55 \mathrm{E}-09$ & $9.07 \mathrm{E}-09$ & 0.28 \\
92 & $1.40 \mathrm{E} 5$ & $1.10 \mathrm{E}-09$ & $1.10 \mathrm{E}-08$ & 0.10 \\
\hline Omitting & He and U data, the average ratio is: & & 1.26 \\
\hline
\end{tabular}




\section{Conclusions}

Since the survival curve obtained by Roots with $\gamma$-rays is exponential, and the measured cross sections agree with our calculations for 1-hit detectors, we conclude that both SSB and DSB of SV-40 virus in EO buffer act as 1-hit detectors. To us this implies that a single electron passing through a complex made up of the DNA molecule and some adjoining water molecules is capable of inducing either a single or a double strand break, though with different efficiencies.

We seek an explanation for the difference in $D_{37}$ doses for single and double strand breaks; that is, why the $D_{37}$ dose for double strand breaks is 25 times that for single strand breaks. Since this buffer enhances the indirect effect, perhaps a geometric argument is valid here. One might assume that a single energetic electron makes a number of radicals and that the likelihood that 2 radicals from the same electron can diffuse to adjacent portions of 2 strands of DNA is 25 times smaller than the likelihood that these radicals will attack a single strand. This might also explain the surprising result that double strand breaks in this buffer respond as 1-hit detectors.

To induce speculation we have calculated the target molecular weights from the $D_{37}$ doses, using a formula in Dertinger and Jung [7] based on their assumption that $60 \mathrm{eV}$ is the average energy loss per hit. For SSB, we find the target molecular weight to be 4.5 $\times 10^{8}$ Daltons, while for DSB we find the target molecular weight to be $1.7 \times 10^{7}$ Daltons, many times the true molecular weight of $3.5 \times 10^{6}$ Daltons.

We cannot provide quantitative answers to either of these questions and hope that such answers can come from radiation chemists experienced in mechanistic spur-diffusion calculations for heavy ion radiolysis.

\section{Acknowledgement}

This work is sponsored by the United States Department of Energy.

\section{References}

1. Butts, J. J., Katz, R. (1967) Theory of RBE for heavy ion bombardment of dry enzymes and viruses. Radiat Res 30: 855-871.

2. Waligórski, M. P. R., Hamm, RN, Katz R (1986) Radial distribution of dose around the path of a heavy ion in liquid water. Nucl Tracks Radiat Meas 11: 304-319.

3. Katz, R., Sinclair, G. L., Waligórski, M. P. R. (1986) The Fricke dosimeter as a 1-hit detector. Nucl Tracks Radiat Meas 11 :301-307.

4. Waligórski M. P. R., Kim Sun Loh, Katz, R. (1987) Inactivation of dry enzymes and viruses by energetic heavy ions. Radiat Phys Chem 30:201-208.

5. Hamm R. N., Wright, H. A., Katz, R., Turner, J. E., Ritchie, R. H. (1978) Calculated yields and slowing-down spectra for electrons in liquid water: implications for electron and photon RBE. Phys Med Biol 23:1149-1161.

6. Roots, R., Holley, W., Chatterjee, A., Rachal, E., Kraft, G. (1989) The influence of radiation quality on the formation of DNA breaks. Adv Space Res 9:45-55.

7. Dertinger, H., and Jung, H. (1970) Molecular radiation biology. Springer, New York-Berlin-Heidelberg. 